\title{
Produção, valor nutricional e eficiências de recuperação e utilização do nitrogênio de silagens de milho sob diferentes doses de adubação nitrogenada
}

\section{Production, nutritional value and recovery efficiencies and nitrogen utilization of corn silage under different doses of nitrogen fertilizer}

\author{
Luis Fernando Glasenapp de Menezes ${ }^{1 *}$; Ricardo Ronsani²; Paulo Sérgio Pavinato ${ }^{3}$; \\ Ronaldo Rubens Biesek ${ }^{2}$; Carlos Eduardo Kruger da Silva²; \\ Clederson Martinello ${ }^{2}$; Bruno Cappellesso ${ }^{2}$; Magali Floriano da Silveira ${ }^{4}$
}

\begin{abstract}
Resumo
O objetivo deste experimento foi avaliar a produção e a qualidade da silagem de milho com diferentes níveis de nitrogênio. Foram utilizados quatro níveis diferentes de nitrogênio, sendo: 0; 80; 160; $240 \mathrm{~kg} \mathrm{ha}^{-1}$ de nitrogênio. O delineamento experimental utilizado foi o de blocos ao acaso com seis repetições. Os dados foram submetidos à análise de variância e à análise de regressão polinomial. A ensilagem foi realizada manualmente em tubos de $P V C$ de $10 \mathrm{~cm}$ de diâmetro e $50 \mathrm{~cm}$ de altura. Foram avaliados os parâmetros produtivos, morfológicos, eficiências fisiológicas, de recuperação e de utilização do nitrogênio, além das variáveis bromatológicas das silagens. A altura da planta (Altura = $1,72+0,067 *$ bloco $+0,0004 * \mathrm{~N}$ ) e produção total (Produção total $=13883,42+786,41 *$ bloco $+18,65 * \mathrm{~N}$ ) responderam positivamente ao incremento da dose de nitrogênio. Na medida em que houve incremento na quantidade de nitrogênio aplicado houve diminuição na eficiência de recuperação ( $R A N=1,027$ $0,00283 * \mathrm{~N})$ e na eficiência de utilização do nitrogênio $(\mathrm{EUN}=42,89-0,11 * \mathrm{~N})$. A proteína bruta da silagem apresentou resposta quadrática $\left(\mathrm{PB}=5,820+0,018 \mathrm{x}-0,00005 \mathrm{x}^{2}\right)$ de acordo com o aumento na dose de nitrogênio. $\mathrm{O}$ acréscimo nas doses de nitrogênio proporcionou melhor produtividade de silagem com alta qualidade. Maiores doses proporcionaram menor eficiência de utilização e de recuperação do nitrogênio.
\end{abstract}

Palavras-chave: Acumulação de nitrogênio, proteína bruta, uréia

\begin{abstract}
The objective of this experiment was to evaluate the yield and quality of corn silage with different nitrogen levels. It was used four levels of nitrogen, $0,80,160,240 \mathrm{~kg} \cdot \mathrm{ha}^{-1}$. The experimental design was randomized blocks with six replications. The data were subjected to analysis of variance and polynomial regression analysis. The silage was performed manually in PVC tubes of $10 \mathrm{~cm}$ diameter and $50 \mathrm{~cm}$ high. The parameters evaluated were productive variable, morphological variable, physiological
\end{abstract}

1 Prof. Dr. do curso de Zootecnia da Universidade Tecnológica Federal do Paraná, UTFPR, campus Dois vizinhos, Estrada para Boa Esperança, Km 4, 85660-000. Dois Vizinhos, PR. E-mail: luismenezes@utfpr.edu.br

2 Discente(s) do curso de Zootecnia da Universidade Tecnológica Federal do Paraná, UTFPR, Campus Dois Vizinhos, Dois Vizinhos, PR. E-mail: ricardoronsani@hotmail.com; biesek_zootecnia_federal@hotmail.com; bruno_kplsso@hotmail.com; cleder.martinello@gmail.com; eduardo_kruger_1@hotmail.com.

3 Prof. Dr. do Programa de Pós-graduação em Zootecnia da UTFPR, Dois Vizinhos, PR. E-mail: pavinato@usp.br

4 Bolsista do Programa Nacional de Pós-Doutorado, PNPD, CAPES, UTFPR, Câmpus Dois Vizinhos, Dois Vizinhos, PR. E-mail: mg_flor@yahoo.com.br

* Autor para correspondência 
efficiency, recovery efficiency and efficiency utilization of nitrogen, and nutritive value of silages. Plant height (height $=1.72+0.067 *$ block $+0.0004 * \mathrm{~N})$ and total production (total production $=13,883.42+$ $786.41 *$ block $+18.65 * \mathrm{~N})$ responded positively according increasing nitrogen dose. The decrease of recovery efficiency $(\mathrm{NAR}=1.027-0.00283 * \mathrm{~N})$ and nitrogen use efficiency $(\mathrm{NUE}=42.89$ to $0.11 * \mathrm{~N})$ with the increase in the amount of nitrogen applied. The crude protein of the silage shown a quadratic response $\left(\mathrm{CP}=5.820+0.018 * \mathrm{~N}-0.00005 \mathrm{~N}^{2}\right)$ according to the increase in nitrogen level. The increase in nitrogen levels provided better productivity with high quality silage. Higher doses showed lower nitrogen utilization efficiency and recovery nitrogen.

Key words: Accumulation of nitrogen, crude protein, urea

\section{Introdução}

Nas regiões do Brasil que se concentra a produção animal intensiva, como a produção leiteira, a eficiência na produção de silagem é um fator importante na lucratividade do sistema. Entre os vários fatores que afetam a eficiência na produção de silagens, se destacam a escolha do material genético (MARTIN et al., 2011), as condições edafo-climáticas e o nível de adubação nitrogenada (NEUMANN et al., 2005).

A qualidade do material ensilado também é um fator determinante no desempenho do animal alimentado com estes produtos, sendo que o mesmo melhora com o aumento no conteúdo de grãos na forragem (ALMEIDA et al., 2003). O teor de MS por ocasião da ensilagem influi muito sobre a natureza da fermentação e conservação da massa ensilada. Segundo Mc Cullogh (1977) os teores ideais de MS devem estar entre 28-34\%. O conteúdo de água da planta forrageira ensilada foi o fator mais importante em determinar a qualidade da silagem resultante, pois alto teor de umidade $(75-80 \%$ ou mais) correlacionou-se significativamente com características indesejáveis, ou seja, ácido butírico e bases voláteis.

Segundo Neumann et al. (2005) a cultura de milho destinada para silagem tem exigência quanto a fertilidade diferenciada daquela para produção de grãos, pois no processo de produção de silagem, em que toda a parte aérea da cultura é colhida, a exportação de nitrogênio é mais acentuada. Além do nitrogênio, os pesquisadores citaram a extração do solo de outros elementos como o enxofre, potássio, cálcio, magnésio e microelementos como zinco, cobre e manganês, entre outros.

A procura pela dosagem ideal de nitrogênio visa o melhor desempenho da planta, principalmente em relação à produtividade. Alguns pesquisadores já estudaram o efeito de doses crescentes de nitrogênio na produção de silagem. Neumann et al. (2005) estudando quatro doses de nitrogênio $(0 ; 45$; 90 e $135 \mathrm{~kg}$ de $\mathrm{N} \mathrm{ha}^{-1}$ ), observaram incremento na produção de grãos, maior rendimento de matéria verde e de matéria seca e menor número de folhas secas na planta para ensilagem. Além disso, não observaram diferença nos custos de produção por unidade de matéria seca. Carvalho, Pinho e Vide (2011), testando até $160 \mathrm{~kg}$ de $\mathrm{N} \mathrm{ha}^{-1}$, observaram que a resposta nas eficiências de utilização desse nutriente depende do tipo de híbrido utilizado, mas a cultura sempre responde a aplicação deste nutriente.

Além do desempenho da planta, devem-se observar as possíveis perdas de $\mathrm{N}$, uma vez que essa perda pode gerar problemas econômicos, ambientais, de saúde pública e de segurança alimentar (CARVALHO; PINHO; VIDE, 2011). Portanto, encontrar a dose de nitrogênio que proporcione boa produtividade, silagem de qualidade bromatológica elevada e de maneira sustentável é de suma importância. O objetivo deste trabalho foi determinar a dose de nitrogênio que permita alta produção e boa qualidade de silagem de milho. 


\section{Material e Métodos}

O experimento foi realizado na área experimental da Universidade Tecnológica Federal do Paraná (UTFPR) - Campus Dois Vizinhos- PR, sendo o cultivo do milho realizado de 10/09/2009 a 18/12/2009. A região faz parte do terceiro planalto paranaense, localizada no Sudoeste do Paraná, com altitude de $520 \mathrm{~m}$, latitude de $25^{\circ} 44^{\prime \prime}$ Sul e longitude de $53^{\circ} 04^{\prime \prime}$ Oeste, sendo o clima do tipo subtropical úmido mesotérmico (Cfa), segundo a classificação de Köepen (OMETTO, 1981). O solo é classificado como Nitossolo Vermelho Distroférrico de textura argilosa (EMBRAPA, 2006). Na tabela 1 estão apresentadas as características químicas do solo anteriormente a implantação do experimento, sendo que, de modo geral, o solo estava com boa fertilidade, com pH ideal para a cultura e teores de $\mathrm{P}, \mathrm{K}, \mathrm{Ca}$ e $\mathrm{Mg}$ considerados altos para esse tipo de solo, na camada de 0-10 cm (CQFS RS/SC, 2004).

Na tabela 2 está demonstrada a precipitação que ocorreu durante o período em que o trabalho estava em execução, durante os meses de setembro a dezembro, segundo o INMET de Dois Vizinhos do ano de 2009.

Tabela 1. Características químicas do solo no momento da implantação do milho. Dois Vizinhos, PR. 2009.

\begin{tabular}{cccccccccccc}
\hline Prof & $\mathrm{pH}$ & $\mathrm{MO}$ & $\mathrm{P}-M e h l i c h$ & $\mathrm{~K}$ & $\mathrm{Ca}$ & $\mathrm{Mg}$ & $\mathrm{Al}$ & $\mathrm{H}+\mathrm{Al}$ & $\mathrm{SB}$ & $\mathrm{T}$ & $\mathrm{V}$ \\
\hline$(\mathrm{cm})$ & $\mathrm{CaCl}_{2}$ & $\%$ & $\mathrm{mg} \mathrm{dm}^{-3}$ & & ----------------- & $\mathrm{cmol}_{\mathrm{c}} \mathrm{dm}^{-3}$-------------------- & & $(\%)$ \\
\hline $0-10$ & 5,50 & 5,09 & 19,98 & 0,30 & 7,22 & 4,23 & 0,00 & 3,84 & 11,75 & 15,59 & 75,4 \\
$10-20$ & 4,90 & 4,42 & 4,48 & 0,10 & 4,43 & 2,64 & 0,12 & 4,96 & 7,17 & 12,13 & 59,1 \\
\hline
\end{tabular}

Fonte: Elaboração dos autores.

Tabela 2. Dados meteorológicos Dois Vizinhos (INMET).

\begin{tabular}{lcccc}
\hline & \multicolumn{4}{c}{ Meses do ano } \\
\cline { 2 - 5 } Dados & Set/09 & Out/09 & Nov/09 & Dez/09 \\
\hline Precipitação & 54,2 & 66,2 & 40,2 & 34,4 \\
$\mathrm{~T}^{\circ}$ máxima - media & 24,1 & 27,2 & 30,6 & 29,7 \\
$\mathrm{~T}^{\circ}$ mínima - média & 14 & 15,8 & 19,7 & 19,4 \\
\hline
\end{tabular}

Fonte: Elaboração dos autores.

Foram avaliadas as características agronômicas quantitativas da planta em função das dosagens de $\mathrm{N}$ para a produção da silagem, respectivamente: 0 ; $80 ; 160$ e $240 \mathrm{~kg} \mathrm{~N} \mathrm{ha}^{-1}$ que foram aplicadas em cobertura em dois períodos, 4-5 folhas e 7-8 folhas completamente abertas, metade da dose em cada aplicação para os respectivos tratamentos.

A lavoura de milho foi implantada em sistema de plantio direto, em sucessão a aveia preta (Avena strigosa cv. IAPAR 61) a qual foi dessecada com herbicida a base de glifosato. Na semeadura foi utilizado o hibrido 380 da DEKALB, em espaçamento entre linhas de $80 \mathrm{~cm}$, profundidade média de $4 \mathrm{~cm}$ e sete sementes por metro linear. Quinze dias após a germinação foi realizado desbaste manual para que todas as parcelas apresentassem população de 70.000 plantas por hectare.

$\mathrm{O}$ delineamento experimental foi o de blocos casualizados, composto por quatro tratamentos e seis repetições. As unidades experimentais foram de dimensões de 10 x $20 \mathrm{~m}\left(200 \mathrm{~m}^{2}\right)$. A adubação de base foi constituída de $20 \mathrm{~kg}$ de $\mathrm{N} \mathrm{ha}^{-1}, 80 \mathrm{~kg}$ de $\mathrm{P}_{2} \mathrm{O}_{5}$ ha $^{-1}$ e $80 \mathrm{~kg}$ de $\mathrm{K}_{2} \mathrm{O}$ ha $^{-1}$, aplicados via adubo formulado 5-20-20, na dose de $400 \mathrm{~kg} \mathrm{ha}^{-1}$, conforme recomendação da CQFS RS/SC (2004). 
As plantas de milho foram colhidas em $16 / 12 / 2009$, entre os estádios reprodutivos de grão pastoso a farináceo, para produção de silagem de planta inteira. Na colheita, procedeu-se a avaliação agronômica, coletando-se as plantas da área útil da parcelam cortando-as a $20 \mathrm{~cm}$ do solo. Posteriormente, as plantas amostradas foram pesadas e medidas. A adoção desse método permitiu determinar o peso seco do colmo, folhas e espiga. Após serem pesados e separados, os componentes das plantas foram secados em estufa de ventilação forçada a $55^{\circ} \mathrm{C}$ por 72 horas ou até peso contante, para estimar o teor de matéria seca, conforme Williams (1994).

Foram coletados cinco quilos da matéria verde do material triturado em ensiladeira para a ensilagem. A ensilagem foi realizada manualmente em tubos de PVC de $10 \mathrm{~cm}$ de diâmetro e $50 \mathrm{~cm}$ de altura (chamados microsilos), onde foi utilizada uma densidade de $500 \mathrm{~kg} \mathrm{~m}^{-3}$ para o armazenamento. A silagem permaneceu 35 dias nos microsilos, para que ocorresse a fermentação e estabilização, conforme o procedimento em silo normal. Após este período, os microsilos foram desmontados, sendo retirado aproximadamente $300 \mathrm{~g}$ da silagem de cada unidade experimental para determinar a matéria seca, as quais foram colocadas em estufa de ventilação forçada a $55^{\circ}$ por 72 horas. Após secagem das amostras, as mesmas foram moídas em moinho Willey para posteriores análises em laboratório.

As análises laboratoriais, procedidas no laboratório de bromatologia da Universidade Tecnológica Federal do Paraná (UTFPR) - Câmpus Dois Vizinhos, constaram da determinação dos teores de proteína bruta $(\% \mathrm{~PB})$, fibra em detergente neutro (\%FDN), fibra em detergente ácido (\%FDA) e matéria seca (\%MS), segundo metodologia descrita por Goering e Van Soest (1970).

Os valores de acúmulo de $\mathrm{N}$ foram obtidos por meio do produto entre o teor de $\mathrm{N}$ na planta e a produção de massa seca (MS). Com os dados de MS e acúmulo de $\mathrm{N}$, foram calculados os seguintes índices, conforme Fageria (1998):
Eficiência fisiológica (EF): é a produção biológica obtida (grãos + palha, em culturas anuais) por unidade de nutriente acumulado, podendo ser calculada pelo estimador:

$$
E F=\frac{Y_{f}-Y_{f}}{N_{a b f}-N_{a b o}}\left(k g * k^{-1}\right)
$$

em que: Yf é a produção total de matéria seca, em $\mathrm{kg}$, com adubação; Y0 é a produção total de matéria seca, em kg, sem adubação; Nabf é o acumulo de nutriente com adubação, em kg; Nab0 é o acumulo de nutriente sem adubação, em kg.

Eficiência de recuperação do nitrogênio aplicado (RAN): é a quantidade de nutriente acumulado por unidade de nutriente aplicado, podendo ser calculada através da equação:

$$
\mathrm{RAN}=\frac{\mathrm{QN}_{\mathrm{f}-} \mathrm{N}_{0}}{\mathrm{Q}_{\mathrm{f}}}\left(\mathrm{kg} * \mathrm{~kg}^{-1}\right)
$$

sendo que: QNf é a acumulação de nutriente, em kg, com adubação; N0 é a acumulação de nutriente, em $\mathrm{kg}$, sem adubação; Qf é a quantidade do nutriente aplicado, em kg.

A eficiência de utilização de nitrogênio (EUN) foi calculada por meio da seguinte equação:

$$
E U N=E F x R A N\left(\mathrm{~kg} \mathrm{~kg}^{-1}\right)
$$

sendo que: $E F$ é eficiência fisiológica e $R A N$ é eficiência de recuperação de N.

Os dados coletados para cada parâmetro foram submetidos à análise de variância e à análise de regressão polinomial, considerando a variável nível de adubação nitrogenada, através do procedimento "proc reg" do programa SAS (2000).

O modelo estatístico utilizado foi o seguinte:

$$
\text { Yijk }=\mu+\mathrm{Ni}+\mathrm{Bj}+\mathrm{Bj}(\mathrm{N}) \mathrm{i}+\text { Eijk; em que }
$$

Yijk = variáveis dependentes; $\mu=$ média das observações; $\mathrm{Ni}=$ efeito do nível de adubação nitrogenada de ordem " $\mathrm{i}$ ”; $\mathrm{Bj}$ = efeito do bloco de ordem “ "j”; $\mathrm{Bj}(\mathrm{N}) \mathrm{i}=$ efeito aleatório baseado no bloco dentro do tratamento (Erro a); $i=1 \ldots .4$ (índice dos 
tratamentos); $\mathrm{j}=1$.... 3 (índices de repetições); e Eij = erro aleatório residual, assumindo distribuição normal média igual a zero e variância o2 (Erro b).

\section{Resultados e Discussão}

A altura das plantas e a produção de matéria seca foram influenciadas positivamente pelo aumento na dose de nitrogênio, enquanto a composição botânica da planta não foi influenciada pelas diferentes doses (Tabela3).Aaltura das plantas aumentou linearmente $($ ALTURA $=1,72+0,067 *$ bloco $+0,0004 * \mathrm{~N})$ com o acréscimo na quantidade de N. Neumann et al. (2005) também observaram incremento na altura das plantas quando elevaram a dose de $\mathrm{N}$ até $135 \mathrm{~kg}$ ha $^{-1}$. A adição de $\mathrm{N}$ em plantas de milho estimula a proliferação do sistema radicular, com conseqüente desenvolvimento da parte aérea (FANCELLI, 1997). Além disso, Karlen Flannery e; Sadler (1988) afirmaram que o N está associado, dentre outras funções na planta, ao crescimento vegetativo. Uma planta bem nutrida em $\mathrm{N}$ apresenta maior crescimento da área foliar e do sistema radicular, pois este nutriente influencia a divisão, a expansão celular e a fotossíntese, o que leva ao aumento da altura de plantas (BÜLL; CANTARELLA, 1993; VARVEL; SCHPERS; FRANCIS, 1997).

Tabela 3. Médias e erros-padrão para os parâmetros produtivos e morfológicos de silagem de milho sob diferentes níveis de nitrogênio.

\begin{tabular}{lcccc}
\hline \multirow{2}{*}{ Variáveis } & \multicolumn{4}{c}{ Doses de nitrogênio $\left(\mathrm{kg} \mathrm{ha}^{-1}\right)$} \\
\cline { 2 - 5 } & 0 & 80 & 160 & 240 \\
\hline Altura da planta (m)*1 & $1,81 \pm 0,023$ & $1,91 \pm 0,028$ & $1,86 \pm 0,025$ & $1,94 \pm 0,025$ \\
Prod. total (kg MS ha $\left.{ }^{-1}\right)^{* 2}$ & $14820,5 \pm 622,0$ & $17736,15 \pm 761,8$ & $16845,44 \pm 684,9$ & $19977,12 \pm 684,9$ \\
Participação (\%) & & & \\
Grão & $29,29 \pm 2,89$ & $28,44 \pm 3,55$ & $29,56 \pm 3,19$ & $28,02 \pm 3,19$ \\
Sabugo & $26,25 \pm 1,68$ & $25,65 \pm 2,05$ & $26,85 \pm 1,85$ & $25,39 \pm 1,85$ \\
Folha & $21,55 \pm 1,79$ & $21,48 \pm 2,2$ & $20,92 \pm 1,95$ & $23,37 \pm 1,95$ \\
Colmo & $22,91 \pm 2,23$ & $24,44 \pm 2,73$ & $22,67 \pm 2,45$ & $23,22 \pm 2,45$ \\
\hline
\end{tabular}

$* \mathrm{P}<0,05$

${ }^{1}$ Altura $=1,72+0,067 *$ bloco $+0,0004 * \mathrm{~N} ; \mathrm{R}^{2}=0,47 ; \mathrm{CV}=3,32 ; \mathrm{P}=0,009$

${ }^{2}$ Produção total $=13883,42+786,41 *$ bloco $+18,65 * \mathrm{~N} ; \mathrm{R}^{2}=0,57 ; \mathrm{CV}=9,85 ; \mathrm{P}=0,003$

Fonte: Elaboração dos autores.

Alguns pesquisadores observaram resposta quadrática da altura da planta com o aumento na dose de nitrogênio. Cruz et al. (2008) observaram altura máxima quando aplicaram $90 \mathrm{~kg}$ de $\mathrm{N} \mathrm{ha}^{-1} \mathrm{e}$ Silva, Oliveira e Silva (2003) encontraram a maior altura aplicando-se $130 \mathrm{~kg}$ de $\mathrm{N} \mathrm{ha}^{-1}$, explicando que, até determinadas doses de $\mathrm{N}$ a planta continua a crescer; depois disso, o auto-sombreamento das plantas, assim como o sombreamento mútuo entre plantas, contribui para a redução do crescimento. Mas a variabilidade de condições experimentais torna um pouco difícil a generalização entre resultados de literatura, pois há muita variabilidade de solo, clima, manejo e cultivar avaliada.

Do ponto de vista de produção de silagem a maior altura de plantas é desejável, uma vez que essa característica está associada à maior produção de massa. Houve resposta positiva na produção de matéria seca (PRODUÇÃO= $13883,42+786,41 *$ bloco $+18,65 * \mathrm{~N})$ à medida que houve aumento na quantidade de $\mathrm{N}$ aplicado (Tabela 3). Neumann et al. (2005) e Oliveira e Caíres (2003) observaram respostas positivas para produção de 
matéria seca sob doses de até $135 \mathrm{~kg} \mathrm{ha}^{-1}$ ou doses residuais de 100 e $150 \mathrm{~kg} \mathrm{ha}^{-1}$ de $\mathrm{N}$ em relação a testemunha, respectivamente. Segundo Neumann et al. (2005) a avaliação do efeito da adubação nitrogenada em cobertura na cultura do milho é uma prática importante no contexto da fertilização de plantas, contribuindo para a diluição dos custos de produção, uma vez que se consegue maior produção total em uma mesma área.

A dose de nitrogênio não influenciou a composição física percentual da estrutura da planta, grão, sabugo, folha e colmo (Tabela 3). Neumann et al. (2005) observaram efeito das doses de N sobre a percentagem de colmo e participação de grãos. Mello et al. (1999) relataram que a maior altura de plantas reduz a qualidade da silagem produzida, uma vez que aumenta a percentagem de colmo na MS total a ser ensilada, podendo, inclusive, diminuir a qualidade bromatológica da silagem.

Observou-se que, apesar de apresentar produção de MS dentro da média (15 a 23 mil kg ha $^{-1}$ ) relatada em trabalhos desenvolvidos no Brasil e no exterior, (ALMEIDA FILHO, 1996), a percentagem de grãos, neste trabalho, apresentou-se abaixo dos valores de 40 a 50\%, recomendada por Nussio (1990) para preparo de silagem de boa qualidade.

Além do aumento da produtividade, o destino final dos nutrientes utilizados é também um fator a ser considerado no processo produtivo, pois as perdas de nutrientes, principalmente o $\mathrm{N}$, são importantes quando se considerar o ambiente como um todo. Essa perda pode trazer conseqüências econômicas, ambientais, de saúde pública e de segurança alimentar (CARVALHO; PINHO; VIDE, 2011). Segundo esses pesquisadores, a eficiência é definida como a capacidade da planta em adquirir o nutriente para incorporá-lo e utilizá-lo na produção de biomassa ou material vegetal de rendimento econômico, caso o mesmo não seja incorporado, estará suscetível à lixiviação, escoamento superficial ou volatilização, com alto potencial contaminante.

Não foi detectada diferença para eficiência fisiológica (EF), que representa a produção biológica obtida por unidade de nutriente aplicado (Tabela 3 ). Esse resultado concorda com aquele encontrado por Carvalho, Pinho e Vide (2011), quando compararam diferentes híbridos recebendo 40 ou $160 \mathrm{~kg}$ de $\mathrm{N}$ $\mathrm{ha}^{-1}$. Esse resultado sugere que a produção biológica não foi um fator determinante na produção.

A eficiência de recuperação do N (RAN) aplicado foi influenciada pela dose de nitrogênio, diminuindo a eficiência com o aumento da dose (Tabela 4). Observou-se que a eficiência de recuperação reduziu $47,85 \%$ quando se elevou a dose de nitrogênio de 80 para $160 \mathrm{~kg} \mathrm{ha}^{-1}$. Lupatini et al. (1995) afirmaram que a planta possui capacidade limitada de utilização do $\mathrm{N}$ em determinado período de tempo. Como o $\mathrm{N}$ é um elemento que é facilmente perdido no sistemaatmosfera, quanto mais tempo permanece livre no solo, maiores são as perdas.

As perdas por volatilização do $\mathrm{N}$ da uréia aplicada ao solo dependem dos seguintes fatores: velocidade com que ocorre a hidrólise, temperatura, tempo, umidade, teor de matéria orgânica, dose de N aplicada, pH e CTC do solo (MELLO, 1987). As perdas podem ocorrer por volatilização que está relacionada a forma de aplicação e fonte de $\mathrm{N}$ utilizada, e por lixiviação do nitrato após reações de nitrificação (SARTOR, 2009), sendo então limitada a permanência do elemento no sistema. Provavelmente, para que houvesse melhor recuperação, as doses maiores deveriam ser fracionadas mais vezes, ficando menos tempo disponível no solo. 
Tabela 4. Médias para o nitrogênio acumulado no material ensilado, eficiência fisiológica (EF), eficiência de recuperação (RAN) e eficiência de utilização do nitrogênio (EUN) de silagem de milho sob diferentes níveis de nitrogênio.

\begin{tabular}{lcccc}
\hline $\begin{array}{l}\text { Dose de } \mathrm{N} \\
\left(\mathrm{kg} \mathrm{ha}^{-1}\right)\end{array}$ & $\begin{array}{c}\text { N acumulado } \\
\left(\mathrm{kg} \mathrm{ha}^{-1}\right)\end{array}$ & $\begin{array}{c}\mathrm{EF} \\
\left(\mathrm{kg} \mathrm{kg}^{-1}\right)\end{array}$ & $\begin{array}{c}\text { RAN* } \\
(\%)\end{array}$ & $\begin{array}{c}\text { EUN** } \\
\left(\mathrm{kg} \mathrm{kg}^{-1}\right)\end{array}$ \\
\hline 0 & 129,02 & - & - & - \\
80 & 197,08 & 46,40 & 85,00 & 36,45 \\
160 & 200,43 & 42,48 & 44,33 & 17,71 \\
240 & 224,78 & 47,75 & 39,75 & 18,28 \\
\hline $\mathrm{CV}$ & - & 33,56 & 37,32 & 38,07 \\
$\mathrm{P}>\mathrm{F}$ & - & 0,9015 & 0,0353 & 0,0415 \\
\hline
\end{tabular}

$*$ RAN $=1,027-0,00283 * \mathrm{~N} ; \mathrm{R}^{2}=0,48$.

$* * \mathrm{EUN}=42,89-0,11 * \mathrm{~N} ; \mathrm{R}^{2}=0,42$.

Fonte: Elaboração dos autores.

A taxa de recuperação de $\mathrm{N}$ ideal seria de valores próximos a $100 \%$, o que na maioria das vezes não se consegue. Carvalho, Pinho e Vide (2011) observaram taxa de recuperação de 49 a 104\%, avaliando a produção de grãos de diferentes cultivares de milho. Sartor (2009), por sua vez, observou recuperação acima de $100 \%$ (110,04\%). Essas duas pesquisas trabalharam com produtos diferentes do presente estudo (grão de milho e pastagem de papuã), tendo outros fatores interferindo (ciclagem de nutrientes, maior teor de $\mathrm{N}$ no solo). Porém, no caso do presente estudo a RAN foi de $85 \%$ na dose de $80 \mathrm{~kg} \mathrm{ha}^{-1}$ e reduziu com o aumento da dose de $\mathrm{N}$, em função de possíveis perdas no solo.

Observou-se que a eficiência na utilização do nitrogênio diminuiu $51,41 \%$ quando se elevou de

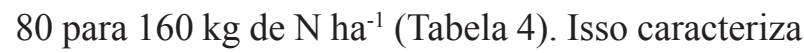
prováveis perdas de nitrogênio e limitações na absorção de $\mathrm{N}$ em maiores doses. Essa redução na eficiência de utilização do $\mathrm{N}$ com o aumento da dose se deve, além do menor aproveitamento pelas plantas, às limitações fisiológicas, às possíveis perdas por lixiviação e volatilização do $\mathrm{N}$ e ao possível desequilíbrio nutricional em altas doses (MELLO, 1987).

A qualidade da silagem é tão importante quanto a produtividade, uma vez que quanto maior a qualidade nutricional do volumoso, menor é o custo com o concentrado utilizado. A dose de nitrogênio afetou quadraticamente $(\mathrm{PB}=$ $\left.5,820+0,018 * \mathrm{~N}-0,00005 * \mathrm{~N}^{2}\right)$ o teor de proteína bruta na dieta (Tabela 5), sendo que o teor máximo de PB estimado pela equação seria na dose de 180 kg de N ha-1. Segundo Church (1988) a dieta de ruminantes deve conter no mínimo $7 \%$ de proteína bruta, para fornecer o mínimo necessário de $\mathrm{N}$ ao desenvolvimento normal das bactérias ruminais, garantindo, assim, uma fermentação eficiente. Observou-se que, com exceção da silagem que não foi fertilizada com $\mathrm{N}$ em cobertura, todas as demais apresentaram valores de proteína bruta igual ou superior a $7 \%$. 
Tabela 5. Média dos valores bromatológicos de silagens de milho fertilizadas com diferentes doses de nitrogênio.

\begin{tabular}{lrrrrc}
\hline \multirow{2}{*}{ Variáveis analisadas } & \multicolumn{5}{c}{ Dose de nitrogênio $\left(\mathrm{kg} \mathrm{ha}^{-1}\right)$} \\
\cline { 2 - 5 } & \multicolumn{1}{c}{0} & \multicolumn{1}{c}{160} & 240 & $\mathrm{P}>\mathrm{F}$ \\
\hline Matéria seca, MS\% & 33,9 & 32,1 & 33,0 & 29,3 & $\mathrm{NS}$ \\
Proteína Bruta, \% & 5,8 & 7,0 & 7,4 & 7,3 & $*$ \\
Fibra em detergente ácido, \% & 22,5 & 25,0 & 22,8 & 24,0 & $\mathrm{NS}$ \\
Fibra em detergente neutro, $\%$ & 51,1 & 50,4 & 51,1 & 51,9 & $\mathrm{NS}$ \\
\hline
\end{tabular}

* $\mathrm{PB}=5,820+0,018 \mathrm{x}-0,00005 \mathrm{x}^{2} ; \mathrm{R}^{2}=0,99$

Fonte: Elaboração dos autores.

A elevação no teor de PB das plantas em relação ao incremento dos níveis de nitrogênio também é atribuída ao aumento na proporção de folhas (CORSI; NUSSIO, 1992). Porém, nesse estudo esse incremento de PB na silagem ocorreu pelo aumento da concentração protéica nas frações da planta, já que a proporção de folhas não foi alterada pela adubação nitrogenada (Tabela 3 ).

Não houve diferença nos teores de MS e de FDN e FDA nas diferentes doses de nitrogênio aplicadas (Tabela 5). Segundo Mc Cullogh (1977) os teores de MS estão na faixa ideal para silagem. Cândido et al. (2002), produzindo silagem de sorgo com diferentes doses de nitrogênio, também não encontraram diferenças nesses compostos na maioria dos híbridos trabalhados. Alguns pesquisadores (MELO et al., 1999) atribuíram maiores teores de FDN à silagem de plantas de maior porte devido ao maior elongamento do colmo. No entanto, pode-se observar que apesar da maior altura das plantas que receberam as maiores doses de $\mathrm{N}$, essa diferença não foi suficiente para alterar o teor de FDN.

\section{Conclusões}

O acréscimo nas doses de nitrogênio proporcionou melhor produtividade de silagem com alta qualidade. Maiores doses proporcionaram menor eficiência de utilização e de recuperação do nitrogênio.

\section{Referênciais}

ALMEIDA FILHO, S. L. Avaliação de cultivares de milho (Zea mays L.) para silagem. 1996. Dissertação (Mestrado em Zootecnia) - Universidade Federal de Viçosa, Viçosa.

ALMEIDA, J. C. C.; REIS, R. A.; RODRIGUES, L. R. A.; FORNASIERI FILHO, D. Avaliação das silagens de cultivares de milho (Zea mays L.) e de sorgo (Sorghum vulgare, pers.) cultivados em quatro densidades de semeadura. Revista Universidade Rural, Série Ciências da Vida, Seropédica, v. 23, n. 1, p. 47-57, 2003.

BÜLL, L. T.; CANTARELLA, H. Cultura do milho - fatores que afetam a produtividade. In: SIMPÓSIO SOBRE FATORES QUE AFETAM A PRODUTIVIDADE DO MILHO E DO SORGO, 1990, Piracicaba. Anais... Piracicaba: Associação Brasileira para Pesquisa da Potassa e do Fosfato, 1993. p. 73-79.

CÂNDIDO, M. J. D.; OBEID, J. A.; PEREIRA, O. G.; CECON, P. R.; QUEIROZ, A. C.de.; PAULINO, M. F.; NETO, M. M. G. Valor nutritivo de silagens de híbridos de sorgo (Sorghum bicolor L. Moench) sob doses crescentes de adubação. Revista Brasileira de Zootecnia, Viçosa, MG, v. 31, n. 1, p. 20-29, 2002.

CARVALHO, R. P. de.; PINHO; R. G. V.; VIDE, L. M. da C. Desempenho de cultivares de milho quanto à eficiência de utilização de nitrogênio. Revista Brasileira de Milho e Sorgo, Sete Lagoas, v. 10, n. 2, p. 108-120, 2011.

$\mathrm{CHURCH}, \mathrm{D}$. C. The ruminant animal digestive physiology and nutrition. Prentice Hall: New Jersey, 1988. $564 \mathrm{p}$.

COMISSÃO DE QUÍMICA E FERTILIDADE DO SOLO - CQFS RS/SC. Manual de adubação e de calagem para os estados do Rio Grande do Sul e Santa Catarina. 10. ed. Porto Alegre: Sociedade Brasileira de Ciência do Solo/Núcleo Regional Sul, 2004. 400 p. 
CORSI, M.; NUSSIO, L. G. Manejo de capim elefante: correção e adubação do solo. In: SIMPÓSIO SOBRE MANEJO DA PASTAGEM, 10., 1992, Piracicaba. Anais... Piracicaba: Fundação de Estudos Agrários Luiz de Queiroz, 1992. p. 87-117.

CRUZ, S. C. S.; PEREIRA, FRANCISCO, R. da S.; SANTOS, J. R.; ALBUQUERQUE, A. W. de; PEREIRA, R. G. Adubação nitrogenada para o milho cultivado em sistema plantio direto, no Estado de Alagoas. Revista Brasileira de Engenharia Agrícola e Ambiental, Campina Grande, v. 12, n. 1, p. 62-68, 2008.

EMPRESA BRASILEIRA DE PESQUISA AGROPECUÁRIA - EMBRAPA/CNPS. Sistema brasileiro de classificação de solos. 2 ed. Rio de Janeiro: EMBRAPA Solos, 2006. 306 p.

FAGERIA, N. K. Otimização da eficiência nutricional na produção das culturas. Revista Brasileira de Engenharia Ambiental, Campina Grande, v. 2, n. 1, p. 6-16, 1998.

FANCELLI, A. L. Cultura do milho: a importância da tecnologia. Informações Agronômicas, Piracicaba, v. 1, n. 78. p. 4-6, 1997.

GOERING, H. K.; Van SOEST, P. J. Forage fiber analysis: apparatus reagents, procedures and some applications. Washington, DC: [s:n], 1970. (Agricultural Handbook, 379).

KARLEN, D. L.; FLANNERY, R. L.; SADLER, E. J. Aerial Accumulation and partitioning of nutrients by corn. Agronomy Journal, Madison, v. 80, n. 2, p. 232242, 1988.

MOOJEN, E. L.; RESTLE, J.; SILVA, J. H. S. Avaliação de milheto (Pennisetum americanum (L.) Leeke) sob pastejo com níveis de nitrogênio. Pesquisa Agropecuária Brasileira, Brasília, v. 31, n. 10, p. 715-720, 1995.

MARTIN, T. N.; VENTURINI, T.; API, I.; PAGNONCELli, A.; VIEIRA JUNIOR, P. A. Perfil do manejo da cultura de milho no sudoeste do Paraná. Revista Ceres, Viçosa, v. 58, n. 1, p. 1-8, 2011.

Mc CULLOUGH, M. E. Silage and silage fermentation. Feedstuffs, v. 49, n. 26, p. 49-52, 1977.

MELLO, F. A. F. Uréia fertilizante. Campinas: Fundação Cargil, 1987. 192 p.

MELO, W. M. C.; PINHO, R. G. V.; PINHO, E. V. de R. V.; CARVALHO, M. L. M.; FONSECA, A. H. Parcelamento da adubação nitrogenada sobre o desempenho de cultivares de milho para produção de silagem. Ciências Agrotécnológica, Lavras, v. 23, n. 3, p. 608-616, jul./set. 1999.

NEUMANN, M.; SANDINI, I. E. ; LUSTOSA, S. B. C.; OST, P. R.; ROMANO, M. A.; FALBO, M. K.; PANSERA, E. R. Rendimentos e componentes de produção da planta de milho (zea mays l.) para silagem, em função de níveis de adubação nitrogenada em cobertura. Revista Brasileira de Milho e Sorgo, Sete Lagoas, v. 4, n. 3, p. 418-427, 2005.

NUSSIO, L. G. A cultura do milho e sorgo para a produção de silagem. In: FANCELLI, A. L. (Coord.). Milho. Piracicaba: FEALQ/ESALQ/USP, 1990. p. 58-88.

OLIVEIRA, A, R. H.; OLIVEIRA, F. A.; SANTOS, A. C.; JACOME, A. G. Rendimento e componentes de produção de milho pipoca em função de resíduos de adubação e densidade populacional. Cultura Agronômica, Ilha Solteira, v. 12, n. 1, p. 89-102, 2003.

OLIVEIRA, J. M. S. de; CAÍRES, E. F. Adubação nitrogenada em cobertura para o milho cultivado após aveia preta no sistema plantio direto. Acta Scientiarum Agronomy, Maringá, v. 25, n. 2, p. 351-357, 2003.

OMETTO, J. C. Bioclimatologia vegetal. São Paulo: Ceres, $1981.400 \mathrm{p}$.

SARTOR, L. R. Eficiência de utilização de nitrogênio, fósforo e potássio por plantas de papuã submetidas a diferentes intensidades de pastejo e niveis de nitrogênio. 2009. Dissertação (Mestrado em Agronomia) Universidade Tecnológica Federal do Paraná, Pato Branco.

SAS Institute. SAS/STATÒ. User's guide: statistics, version 8.1. 4. ed. v. 2, Cary:SAS Institute, 2000.

SILVA, P. S. L.; OLIVEIRA, F. H. T. de; SILVA, P. I. B. Efeitos da aplicação de doses de nitrogênio e densidades de plantio sobre os rendimentos de espigas verdes e de grãos de milho. Horticultura Brasileira, Brasília, v. 21, n. 3, p. 454-457, 2003.

VARVEL, G. E.; SCHPERS, J. S.; FRANCIS, D. D. Ability for in-season correction of nitrogen deficiency in corn using chlorophyll meters. Soil Science Society of America Journal, Madison, v. 61, n. 4, p. 1233-1239, 1997.

WILLIAMS, A. G. The permeability and porosity of grass silage as affected by dry matter. Journal of Agriculture Engineering Research, v. 59, n. 2, p. 133-140, 1994. 
